\title{
Study on the Infiltration and Development of Marcuse's Aesthetic Ideology in the Art of Book Design
}

\author{
Ying $\mathrm{Lu}$ \\ Department of Art \\ Guangxi Technological College of Machinery and \\ Electricity \\ Nanning, China 530007
}

\author{
Jing Zhang \\ Department of Art \\ Guangxi Technological College of Machinery and \\ Electricity \\ Nanning, China 530007
}

\begin{abstract}
This paper aims at studying the integral design of modern books from aesthetic characteristics of art forms of books and the construction of aesthetic form based on cultural attributes of books, and it combines Marcuse's aesthetics theory with book design to explore its infiltration in the field of book design.
\end{abstract}

Keywords-Marcuse Aesthetics; Book design; Aesthetic art

\section{INTRODUCTION}

Significance of Marcuse's aesthetic ideology to contemporary designMarcuse was a famous political theorist, philosopher, and esthetician in the West in the twentieth Century. He believed that the fundamental trait of the difference between art and reality, and human activities was that the aesthetic forms of art were different. In social politics, the potential of art must depend on the aesthetic form of Art, the characteristics of art are not in itself contents, but transforming contents into reality, it is not a description and reflection of existing things, but a critique and transcendence of existing things. Marcuse's aesthetic theory is quite different from that formalist aesthetic theory, pure formalism abandons the link between art and reality, and advocates that art should be divorced from reality, while Marcuse thought that art should deny and transcend reality by means of its art forms. Therefore, it can be said that Marcuse's aesthetic theory originated from the formal aesthetics theory, but it was superior than the formal aesthetics theory, it was a kind of depth and extension. Marcuse's aesthetic theory system had a very important position in the history of modern Western Aesthetics, it not only focused on social reality, but also paid attention to human emotion, and had promoted the diversified development of modern aesthetics.

\section{THE DEVELOPMENT OF BOOK DESIGN AT HoME AND ABROAD}

\section{A. Chinese Traditional Design}

In the history of thousands of years, the traditional design

Foundation project: 2014 Youth Fund Project for Humanities and Social Sciences of Ministry of Education (14YJC760080). of our country has evolved into a kind of aesthetic combination of tone and taste. The thought of the Chinese soul has been deeply rooted in people's hearts. In traditional Chinese book design, a variety of traditional binding forms, such as cases, boxes, letters, etc., would be used to protect the books, which embodied the unique beauty of the book in the world. For example, The classic of tea and The classic of wine were excellent representative works in the form design of traditional books. On the basis of traditional book forms, they used wood, pottery, porcelain and other materials to deliver accurate expression of the theme of the book, and on the basis of the ancient books, cultural visual elements like tea and wine were added, which well integrated the technology and process, having a high collection value. This broke the traditional concept of book design, and presented the book design to us in a new, three-dimensional way of thinking, this made China's future art of book design will be more tenacious vitality.

\section{B. Western Design}

In the continuous development of science and technology in today's social situation, people increase the communication and contact between each other, as a result, there are many excellent western design ways introduced into our country, thus the contemporary book design in China presents the western styles. Many designers absorb and draw on western design ways and styles, and they combine with the western art of design, which has gradually formed a modern western style design. For example, Re-No representation designed by Aaron Nieh, is one of the typical excellent works, it is a collection of works designed by the designer himself, in the collection, many of the author's design sketches and ideas are presented in manuscript form, therefore, when people read this book, they can not only accurately grasp the essence of the book, but also can always see the author's thoughts in his works.

\section{Integrated Design}

Contemporary designers are able to capture many of the Western design extracts while drawing on Chinese traditional book design. With the progress of the times, book design should be adapted to the aesthetic habits of readers in 
the contemporary society, you need to constantly create and not rigidly adhere to a certain style to make the designed works have both connotation and market. For example, Famous prose series is a series of essays of the old time, its title and text adopted the combination of traditional blue background and pale yellow, while the ancient woodcut advertising fonts were used in the hollow out position, which had both the flavor of the old age and the sense of modern design, and endowed a new connotation to literary and artistic works.

\section{ART FORMS OF BOOK DESIGN}

In all ages, the progress of human civilization can not be separated from the spread of books. The western has Bible, which made Christianity dominant in Western religions. The East has The Analects of Confucius, which is hailed as the Bible of the East, it had an indelible influence on the development of China's later generations. From this point of view, books have contributed greatly to the spread of human civilization, and this is closely related with the content and the appearance of books. The content of books can be handed down from generation to generation with good binding, book design is the structure construction of the whole beauty of books, it includes the formation of formal beauty and the construction of cultural connotation. Formal beauty refers to the direct embodiment of books from their appearance, while cultural connotation is deeper internal information. Form aesthetics and cultural connotation form the whole aesthetic form of books, thus, the artistic, ornamental and cultural values of books are reflected.

Book design is a three-dimensional thinking activity, including the construction of cover, lining, title page, directory, text and other forms. It makes the content of the book transformed into a complete and orderly form of books, and can achieve the purpose of dissemination of ideological content. The artistic design of books lays the foundation for the dissemination of books and becomes a new form of media. Space composition, vivid images, interesting shapes, and far-reaching contents all make the whole book became a complete work of Art, and enable readers to both get the edification of knowledge and experience the enjoyment of beauty in the process of reading.

Traditional views believed that the relation between the form of Book Art and its cultural connotation was that the sense of form must depend on the content of the book. The fundamental reason of a book to become a work of Art is that its cultural value is very high. But such a conventional view has its limitations, the form and content can not be simply separated, but linked, meanwhile, the form beauty can not be substituted for the unique value-added function of art. Content without form will be tasteless, while, form without content will be hollow and withered. For thousands of years, books have evolved from generation to generation. It has changed from a simple knowledge transmission path to a beautifully designed work of art, which can not be separated from the ingenious combination of form and content, through the designer's careful construction, the original two independent aspects have been transformed into a whole, and the conversion between two forms realizes the transmission of information content. This combination of sensibility and reason can really reflect the value of design.

\section{NEW DESIGN CONCEPT GUIDED BY MARCUSE'S AESTHETICS}

The most distinctive feature of art form advocated by Marcuse aesthetics theory was that it adhered to the criticism and Transcendence to reality, and used words, colors, sounds, etc., to suppress repressed, distorted human and natural potential", so as to break the past shackles and thinking habits of people. From this we can see that Marcuse had always tried to break through and develop on the basis of formal aesthetics, when it came to the narrow sense of formal aesthetics, he would actively seek solutions and breakthroughs to make Marcuse aesthetics become a kind of more generalized aesthetic philosophy studying the social potential of Art, which has a profound influence on book design.

The contemporary art form is a fast food kind art form, under such circumstances, we must further explore the social potential of aesthetics in order to make books work in a unique artistic and cultural value. Marcuse's aesthetic philosophy, as well as his unique perspective and distinctive criticism had provided some possible directions for the development of modern book art.

\section{A. Characteristics of Marcuse's Aesthetic Theory}

After studying the connection between the art of book design and Marcuse's aesthetic philosophy, we can find that the support of aesthetics of Marcuse to the whole design concept of books is very comprehensive. Marcuse always put his eyes on the social level, his broadened vision made his aesthetic more distinctive, beyond reality and be critical. All these are of great significance to the design of books. In today's society, the rapid development of electronic information technology makes the paper version book has been facing an unprecedented bottleneck. In the new media era, electronic books really possess the functions that traditional books can not replace, such as convenient, quick, large amount of information, high efficiency, interactive, etc.. In the face of these challenges, it is the designers' first concern to find out more unique ways and new ideas of book design. Of course, a certain theoretical knowledge have been gained from the analysis and discussion on the aesthetic characteristics of book design from the formal discourse of Marcuse, however, it needs further widening and looking for other theoretical support, and it is an arduous task and the road is long.

Marcuse's aesthetic thought always ran through the concept of form, he argued that form and content were no longer simple divisions, there was no correlation between the two, but a whole that supported each other, they depended on each other. The process of combining form with content was dynamic and changing. Therefore, Marcuse believed that an excellent work of art was bound to be a form to drive content, all the main ideas should be realized under the banner of form, but no longer the old thought of separating formal art from reality. Marcuse hoped to narrow the distance between art and life through 
this form of beauty, deny and transcend reality. It had the following distinctive features:

1) Revolutionary character of Marcuse aesthetics ideology

In the twentieth Century, most of the western aesthetics derive aesthetic theories of various genres based on formalist Aesthetics. Marcuse's aesthetic theory is particularly noticeable among them, while compared to other aesthetic theories, Marcuse esthetics theory has its unique revolutionary characteristics. Marcuse believed that the revolutionary power of the aesthetic form was inherent. First of all, the original material of aesthetic form changed into orderly form from a chaotic state, and the organic combination made the aesthetic form essentially able to order some scattered materials. This is the revolutionary thought of Marcuse's aesthetics theory, it is just this kind of revolution that makes Marcuse's aesthetic theory itself have the characteristics of surpassing reality. The so-called art is to conquer the chaotic and frenzied content of the world with the truth of beauty, so that all these things are conquered by aesthetic forms, man can therefore enjoy beauty.

Undeniably, today's society is more and more filled with material things, and people have no spiritual enjoyment right. The aesthetic vocabulary may be farther and farther to the life itself, Marcuse's aesthetics had also made a revolutionary breakthrough in this respect, he believed that people's spiritual level determined the behavior of material life, and the power to make people change was art. The sublime and joyful spirit shown by art is actually above material life, therefore, the aesthetic form maintains another consideration of the art to the material reality. Revolution is the nature of the aesthetic form of Art, but revolutionary absolutely can not be linked with other material contents, for it is a kind of posture and a kind of potential.

2) Psychological characteristics of Marcuse's aesthetic ideology

Marcuse's aesthetics was an open and social thought, it had a negative and transcendental meaning to reality, and aimed at constructing a theory system of formal aesthetics to solve social problems. So, the aesthetic form needs to change people's psychological needs to achieve the revolutionary features of it, which makes people perceptual cognition higher than rational cognition, when we can be liberated from the rational understanding, we will produce the aesthetic pleasure of art. The aesthetic form of art can organically combine reason with sensibility, and avoid the compulsion of the rational law, while beauty is just the bridge between man and man, as well as man and nature in this society. But in the real life, with the progress of science and technology, people are increasingly accustomed to the rational cognition and locking the thoughts in the side frames, it is just Marcuse's aesthetic theory that makes people dare to deny and surpass reality. Therefore, in the face of the revolutionary problems in reality, Marcuse theory can use art to explain the great influence on human psychology, if we cam integrate the aesthetic form into the people's lives to enable people to appreciate art from a perceptual point of view as Marcuse said, then our life won't be so tired like now, then, everything we think of as fidgety can be turned into entertainment and recreation.

\section{3) Utopian features of Marcuse's aesthetic ideology}

In the long course of evolution, Marcuse's literature has always maintained a theory that art and aesthetics are the media that can make people feel happy and beautiful in reality. Art can be neither a tool for comfort in suffering nor a vassal of politics. Therefore, Marcuse's aesthetic theory is indispensable to have the fantasticality nature of utopia. Utopia was a perfect world, but Marcuse had broken the inherent nature of Utopia, and he believed art must have the ability to negate, criticize, and transcend reality, only in this way can people keep their minds from past rules in real life, like the perfect utopia world, it was entirely unreal, but beautiful vision.

\section{INFLUENCE OF MARCUSE'S AESTHETICS THEORY ON BOOK DESIGN}

\section{A. Whole Book Design Can Not Abandon Its Unique Art Form}

In fact, book design is to reorganize and organize the material in the book to enable the cultural space displayed by books to be separated from reality, so as to expand the thinking and perception ability between the subject and the objective things, therefore, modern book design can not abandon its unique art form. After more than 100 years of development, contemporary book design has changed from the design principle that combined art with life advocated by industrial art into the book design style in pursuit of spiritual expression now, which is more in line with the contemporary psychological and physiological needs. Book design provides more than just a way of communication for writing, but also a kind of embodiment of values and aesthetics. The book design provides an added value for the content of the book, it makes the book get a breakthrough in the artistic value on the basis of the original function, therefore, the design of contemporary books cannot abandon its unique art form.

\section{B. The Overall Design of Books Should be Consistent with the Direction of Cultural Transition}

The consistent direction of book design and cultural transition is determined by the characteristics of the times in book art. Nothing in the world is the same, it changes with the times, and so does the design of books, and, as we've seen, the book deign constantly changes with the transition of culture. Books are created by man, as well as art work used by man, the beautiful and generous appearance of book are inseparable from the unique brand of social culture, this is formed from the so-called culture transition, from the reader's point of view, the basic function of a book is to convey information, where the reflected human feelings can attract readers, while from a view of long term, each design style shall have its own unique design concept, therefore, such aesthetic and design patterns can be passed down.

\section{CONCLUSION}

The whole design of books should embody the reform function of art. The most distinctive part of Marcuse's 
aesthetic ideology is its critical and transcendent nature. Now, it has entered the information age, book design in the information age greatly emphasizes the maximum efficiency of information communication, many designers tend to ignore the reform role of books, but this does not mean that modern book design art can not promote the progress of human civilization. Books have the functions of beautifying life, purifying mind and expanding vision, at the same time, it has the social function surpassing reality, this effect is gradually formed in imperceptible influence, but it enables people to emancipate their minds and escape from imprisonment.

In a word, Marcuse's aesthetic theory has made a great contribution for the design of books, if we want to design a book into a perfect work of Art, it not only requires us to extensively dabble in a variety of aesthetic theories, but also broaden our horizons and seek other theoretical support to let books design more artistic and valuable.

\section{REFERENCES}

[1] Wu Xiaohong.Development status of modern book design[J].Folk Art and Literature,2011.

[2] Jin Yongbing.Study on Marcuse's literary ideology[J].Social Science of Beijing,2002. 